\title{
STUDY OF DEFECT ON 180 ML HDPE BOTTLES YOGURT PRODUCTS WITH SMC B11 EXTRUSION BLOW MACHINE AT PT X
}

\section{KAJIAN DEFECT PADA BOTOL HDPE 180 ML PRODUK YOGURT HEAVENLY DENGAN MESIN EXTRUSION BLOW SMC B11 DI PT X}

\author{
Tommy Prasetya Kana ${ }^{\mathrm{a}}$ dan Handika Dany Rahmayanti ${ }^{\mathrm{a}^{*}}$, HM. Didik \\ ${ }^{a}$ Teknik Grafika, Politeknik Negeri Media Kreatif, Indonesia \\ *Email: handikadany@ polimedia.ac.id
}

\begin{abstract}
The type of plastic packaging that is popular in the community is bottle packaging. The plastic material that is generally used to make plastic bottles is High Density Polyethylene (HDPE). The plastic bottle industry in Indonesia usually uses a blow molding process in its production process, where the blow molding process consists of injection blow molding, extrusion blow molding and stretch blow molding. The SMC B11 machine is one of the extrusion blow molding machines used to produce plastic bottle packaging. In producing workpieces, this machine still produces several products that are not in accordance with company standards, including in terms of production cycle times and product defects. Defects or defects that are often encountered include the appearance of spots, bent parison which causes the bottle to bend (the bottle body is thin one side) and blow pin which causes the thread to not fit.
\end{abstract}

Keywords-Bottle, Plastic, Defect, Extrussion Blow Molding

\begin{abstract}
Abstrak-Jenis kemasan plastik yang populer dimasyarakat adalah kemasan botol. Material plastik yang umumnya digunakan untuk membuat botol plastik yaitu High Density Polyethylene (HDPE). Industri botol plastik di Indonesia biasanya menggunakan proses blow molding dalam proses produksinya, dimana proses blow molding ini terdiri dari proses injection blow molding, extrusion blow molding dan stretch blow molding. Mesin SMC B11 merupakan salah satu mesin extrusion blow molding yang digunakan untuk memproduksi kemasan botol plastik. Dalam memproduksi benda kerja mesin ini masih menghasilkan beberapa produk yang tidak sesuai dengan standar perusahaan diantaranya dari segi waktu siklus produksi dan cacat produk. Cacat atau defect yang sering dijumpai yakni munculnya
\end{abstract}


bintik, parison bengkok yang mengakibatkan botol bengkok (body botol tipis sebelah) dan blow pin yang mengakibatkan ulir tidak sesuai.

\section{Kata Kunci-Botol, Plastik, Defect, Extrussion Blow Molding}

\section{PENDAHULUAN}

Tumbuhnya perekonomian Indonesia secara makro, membawa dampak yang baik terhadap daya beli konsumen (Mufreni, 2016 : 48). Sejalan dengan hal tersebut salah satu sektor yang berkembang adalah usaha industri kemasan, baik kecil maupun besar dengan berbagai macam variasi dan derivasi produk untuk menjawab kebutuhan konsumen. Bahan dasar yang digunakan untuk membuat kemasan saat ini bervariasi mulai dari plastik, kaleng, gelas, kaca, kertas, karton, dan lain-lain. Plastik merupakan jenis kemasan yang sering kita temukan di pasaran. Jenis kemasan plastik yang populer dimasyarakat adalah kemasan botol. Material plastik yang umumnya digunakan untuk membuat botol plastik yaitu High Density Polyethylene (HDPE). Bahan material ini memiliki karakteristik kuat, keras, buram dan lebih tahan terhadap suhu tinggi sehingga cocok untuk mengemas produk seperti Yogurt. Industri botol plastik di Indonesia biasanya menggunakan proses blow molding dalam proses produksinya, dimana proses blow molding ini terdiri dari proses injection blow molding, extrusion blow molding dan stretch blow molding. Mesin
SMC B11 merupakan salah satu mesin extrusion blow molding yang digunakan untuk memproduksi kemasan botol plastik. Permasalahan yang sering dijumpai dalam dunia industri yakni ketidaksesuaian antara bentuk yang direncanakan dengan bentuk hasil dari produksi. Studi kasus yang dilakukan yakni pada mesin Extrusion Blow SMC B11 dengan produk botol Yogurt ukuran $180 \mathrm{ml}$ pada PT X. Dalam memproduksi benda kerja mesin ini masih menghasilkan beberapa produk yang tidak sesuai dengan standar perusahaan diantaranya dari segi waktu siklus produksi dan cacat produk. Cacat atau defect yang sering dijumpai yakni munculnya bintik, parison bengkok yang mengakibatkan botol bengkok (body botol tipis sebelah) dan blow pin yang mengakibatkan ulir tidak sesuai. Oleh karena itu, penulis tertarik mengkaji defect yang terjadi pada botol HDPE $180 \mathrm{ml}$ untuk produk yogurt yang diproduksi dengan mesin extrusion blow SMC B11 di PT X

\section{METODE PENELITITAN}

Blow molding adalah proses manufaktur plastik untuk membuat produkproduk berongga (botol) di mana parison 
yang dihasilkan dari proses ekstrusi dikembangkan dalam cetakan oleh tekanan gas. Pada dasarnya blow molding adalah pengembangan dari proses ekstrusi pipa dengan penambahan mekanisme cetakan dan peniupan. Secara umum ada tiga macam blow molding, yaitu extrussion blow molding, injection blow molding dan stretch blow molding (Ihsan, $2015: 7$ )

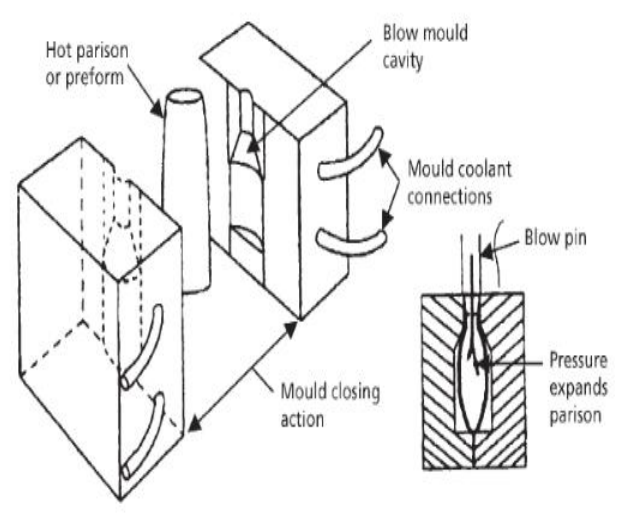

Gambar 1. Proses Dasar pada Blow Molding (Sumber: Lee, 2006)

Menurut Lee (2006 : 1-2) langkahlangkah umum dalam proses blow molding adalah sebagai berikut: 1) Pelelehan resin (bijih plastik). Pelelehan bijih plastik dilakukan oleh extruder yang merupakan bagian dari mesin blow molding. Peralatan yang digunakan ekstruder adalah pemanas (heater) dan sekrup penekan (screw); 2) Pembentukan lelehan plastik dalam bentuk silinder atau tabung. bentuk silinder atau tabung tersebut pada umumnya disebut parison; 3) Setelah pembentukan parisson, parison berada di dalam cetakan dan kemudian ditiup sehingga plastik mengembang dan menekan dinding cavity. Peniupan dilakukan melalui pinyang dimasukkan melalui celah botol. proses peniupan parisson dapat dilihat pada gambar 1 diatas.

Seiring perkembangan teknologi, proses blow molding ikut berkembang menyesuaikan aplikasi penggunaanya yang semakin luas, berdasarkan aplikasi dan prosesnya sendiri blow molding terdiri dari beberapa macam proses, diantaranya sebagai berikut : 1) Injection Blow Molding. Pada proses injection blow molding parison yang dihasilkan sudah memiliki leher dan ulir yang sudah dibentuk untuk dimensi akhirnya yang diinginkan. Proses ini biasanya digunakan untuk menghasilkan botol-botol farmasi kecil dan botol yang memiliki toleransi leher botol dan ulir yang sangat tinggi. Proses injection blow molding diawali dengan proses penginjekan material thermoplastic yang sudah dilelekan ke dalam cavity dan mengelilingi batang core untuk membentuk parison setengah jadi yang disebut preform. Proses selanjutnya cetakan lain menutup dan mengapit preform dan udara di tiupkan sehingga preform membentuk dimensi terakhir yang diinginkan, seperti pada Gambar 2. 


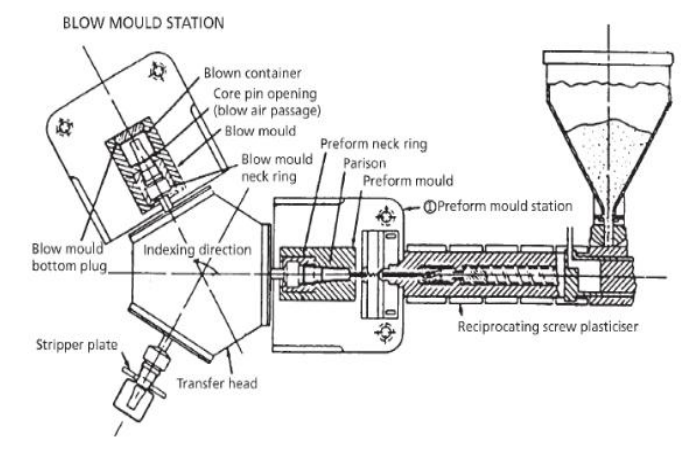

Gambar 2. Proses Injection Blow Molding (Sumber: Lee, 2006)

Selanjutnya 2) Extrusion Blow Molding. Berbeda dengan injection blow molding, pada proses extrusion blow molding material thermoplastic yang sudah dilelehkan akan dikeluar dalam bentuk seperti pipa atau sedotan yang kemudian ditangkap oleh cetakan. Proses pada extrucsion blow molding diawali dengan pelelehan meterial yang kemudian didorong oleh screw menuju die head untuk menghasilkan bentuk seperti pipa, yang kemudian ditangkap oleh cetakan dan dilakukan proses peniupan uadara bertekan sehingga parison membentuk bentuk sesuai cetakan. Proses extrusion blow molding dapat dilihat pada Gambar 3.

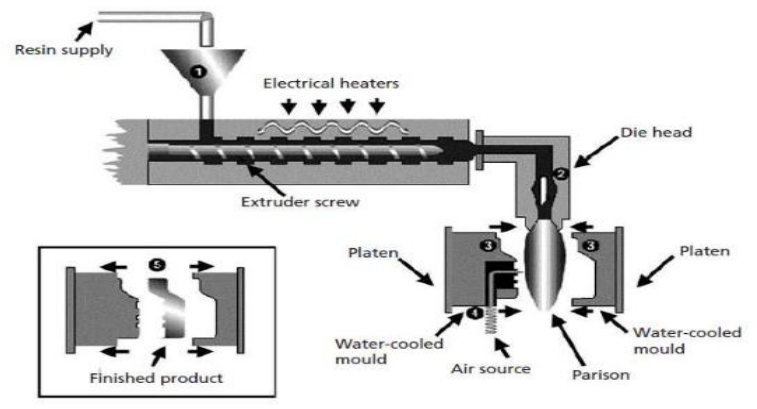

Gambar 3. Proses Extrucsion Blow Molding (Sumber: Lee, 2006)
Kelebihan dari proses extrucsion blow molding adalah pembentukan rogga yang natural, sesuai untuk kemasan dengan volume yang besar. Namun proses ini memiliki kekurangan diantaranya sulit mengatur ketebalan diding produk, dan sulit mengontrol permukaan serta memiliki toleransi dimensi yang lebih besar (Ihsan, 2015 : 10). 3) Strecth blow molding , merupakan pengetahuan baru pada industri blow molding dengan penggunaannya pada botol softdrink. Strecth blow molding mengaplikasikan metod pembuatan kemasan plastik dari sebuah preform yang direntangkan dan ditiup sehingga membentuk sesuai bentuk terakhir yang diinginkan (Ihsan, $2015: 10$ ).

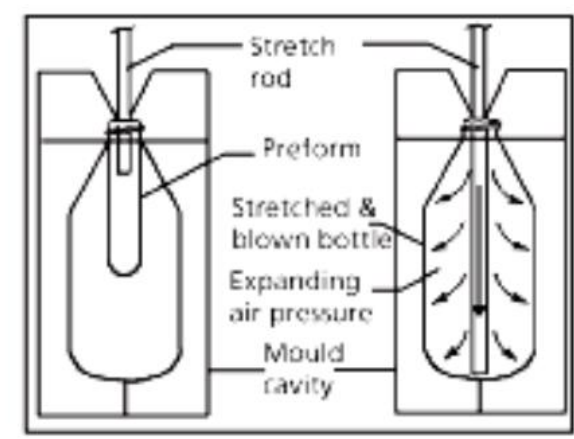

Gambar 4. Stretch Blow Molding (Sumber: Lee, 2006)

\section{HASIL DAN PEMBAHASAN}

Pada saat proses produksi botol HDPE Yogurt $180 \mathrm{ml}$ dengan mesin Extrusion Blow SMC B11 di PT X terdapat beberapa defect yang terjadi seperti bintik, ulir dan body tipis 
sebelah. Defect bintik terjadi pada permukaan produk, seperti ditunjukkan Gambar 5. Defect ini termasuk kategori major defect karena mengurangi kualitas penampilan suatu produk. Selanjutnya ada defect ulir seperti ditunjukkan Gambar 6. Defect inilah yang menyebabkan ketika botol akan di tutup terjadi dol atau tutupan botol tidak sempurna. Defect lain yang terjadi adalah body tipis sebelah seperti yang ditunjukkan Gambar 7 . Biasanya defect ini juga disebut warping atau twisting.

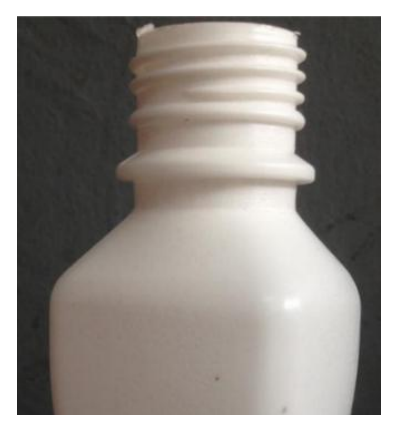

Gambar 5. Defect bintik

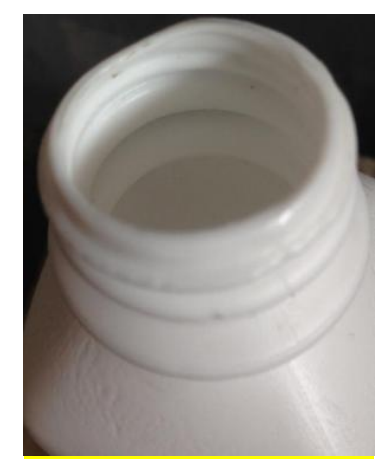

Gambar 6. Defect ulir

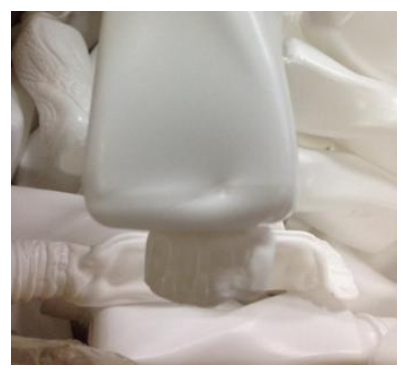

Gambar 7. Defect body tipis sebelah
Adanya defect dapat menurunkan jumlah produksi sehingga target produksi tidak tercapai. Adapun pernyebab terjadinya defect pada saat pproses produksi btol HDPE Yogurt $180 \mathrm{ml}$ dengan mesin Extrusion Blow SMC B11 di PT X adalah sebagai berikut:Defect bitnik, ulir dan body tipis sebelah. Penyebab terjadinya defect bintik pada botol HDPE 180ml botol yogurt karena adanya material yang terkontaminasi oleh kotoran (debu) atau mixing yang (flash) sisa flash yang di olah kembali (pencampuran bahan) pada proses pengilingan bahan, mesin Extrusion Blow memiliki hopper yang berfungsi untuk menampung material atau bahan sebelum dilelehkan didalam barrel.

Material yang kotor ketika proses penggilingan flash dan hopper yang kurang bersih akan mengakibatkan material yang tersimpan didalamnya dapat terkontaminasi. Pembersihan yang kurang bersih akibat dari sisa flash yang tercampur lagi dengan bahan yang baru. Penggilingan yang sampai 3 kali yang di campur lagi dengan bahan yang baru juga bisa mempengaruhi terjadinya bintik.

Penyebab terjadinya defect ulir yang tidak sesuai pada botol HDPE 180ml botol Yoghurt karena adanya tiupan angin yang terjadi pada di blow pie. Di sebabkan karna tekanan tiupan yang berbubah-ubah ketika dalam pemerosesan botol yogurt heavenly berlangsung. Oleh karena itu ulir terkadang 
tidak sesuai dengan bentuk sempurnannya dan menyebabkan ketika botol akan di tutup terjadi dol atau tutupan botol tidak sempurna.

Penyebab terjadinya defect body tipis sebelah ia lah karna parison bengkok ketika lelehan parison tersebut dalam keadaan bengkok ketika meleleh dan lanjut ke dalam mould (pembentukan botol) disana lelehan parison yang bengkok dapat menyebabkan body tipis sebelah. Oleh karnanya parison bengkok dapat banyak menimbulkan body tipis sebelah jika tidak diatasi dengan cepat oleh operator. Alat untuk bisa melihat bahwa body tipis sebalah sikmat dan jangka sorong

Penurunan jumlah produksi akibat terjadinya defect sangat merugikan perusahaan. Oleh karena itu diperlukan solusi untuk mengurangi defect yang terjadi. Adapun solusi yang dilakukan untuk mengurangi defect bintik adalah: sebelum memulai proses produksi harus memeriksa material atau bahan untuk mencegah kemungkinan adanya kontaminasi dan dipastikan sekitar area mixing (Pencampuran) tempat pengilingan steril dari debu yang bisa tercampur pada proses pencampuran bahan, proses pengilingan aval botol hanya bisa sampai 2 kali yang sebelumnya sampai 3 kali tujuannya adalah agar proses pencampurannya tidak banyak aval, pada bagian shift ke-3, produksi dan hopper pada mesin Extrusion Blow B11 dalam keadaan bersih dari kotoran atau material lain.

Hopper dibersihkan terlebih dahulu dengan menggunakan vakum lalu dibersihkan dengan menggunakan kain yang basah sedikit alkohol, hal ini bertujuan supaya agar kotoran yang berada di hopper dibersihkan dari sisa produksi sebelumnya dan kotoran yang berada didalam hopper dapat terangkat.

Solusi untuk meminimalisir terjadinya defect pada bagian ulir. Agar pada proses ini tidak terlalu banyak menimbulkan defect ulir yang tidak sesuai ketika tutup botol (looses) ada dua solusi sebagai berikut: pastikan tidak ada air pendingin netes ke mould dengan cara ini, ketika mould di tiup dengan blow pin tidak ada yang tertiup ketika proses berlangsung dan pastikan blow pin dengan mould sejajar (center) dan tiupan angin blow pin harus sesuai dengan standar 6 sampai 8 bar.

Solusi untuk meminimalisir terjadinya body tipis sebelah pada bagian die head pastikan parison yang keluar sesuai dengaan bentuk ukuran botol yang telah disesuaikan dengan botol. Jika terjadi ketidaksesuaian ada dua solusi yaitu sebagai berikut: Jika tipisnya di bagian depan parison, Tarik ke belakang jadi parison cendrung ke belakang dan begitu sebaliknya jika tipisnya pada bagian belakang parison, tarik ke depan jadi parison cendreng ke depan selanjutnya jika parison yang bodynya tipis sebelah arahkan parison yang 
tebal atau cenderung parison bengkok ke arah yang tebal dengan cara menyetel bagian die pin nya agar sesuai dengan ukuran botolnya kembali.

Adapun solusi lainnya yang perlu dilakukan untuk mengurangi defect pada saat proses produksi botol HDPE Yogurt Heavenly $180 \mathrm{ml}$ dengan mesin Extrusion Blow SMC B11 di PT Jayatama Selaras adalah dengan mengontrol parameter seperti pada tabel berikut ini:

Tabel 1. Kontrol Parameter Extrusion Blow

\begin{tabular}{|c|c|c|c|c|}
\hline No & Parameter & Standar & $\begin{array}{l}\text { Sebelum } \\
\text { diperbaki }\end{array}$ & $\begin{array}{r}\text { Setelah } \\
\text { diper- } \\
\text { baiki }\end{array}$ \\
\hline 1 & $\begin{array}{c}\text { Temperature } \\
\text { barrel }\end{array}$ & $\begin{array}{l}160- \\
180\end{array}$ & 150 & 160 \\
\hline 2 & $\begin{array}{c}\text { Temperature } \\
\text { heater } 1\end{array}$ & $\begin{array}{l}160- \\
180\end{array}$ & 185 & 180 \\
\hline 3 & $\begin{array}{c}\text { Temperature } \\
\text { heater } 2\end{array}$ & $\begin{array}{l}160- \\
180\end{array}$ & 155 & 160 \\
\hline 4 & $\begin{array}{c}\text { Temperature } \\
\text { heater } 3\end{array}$ & $\begin{array}{l}160- \\
180\end{array}$ & 185 & 180 \\
\hline 5 & $\begin{array}{c}\text { Temperature } \\
\text { heater } 4\end{array}$ & $\begin{array}{l}160- \\
180\end{array}$ & 155 & 160 \\
\hline 6 & $\begin{array}{l}\text { Temperature } \\
\text { heater head }\end{array}$ & $\begin{array}{l}160- \\
180\end{array}$ & 190 & 180 \\
\hline 7 & $\begin{array}{c}\text { Temperature } \\
\text { nozzel }\end{array}$ & $\begin{array}{l}160- \\
180\end{array}$ & 195 & 180 \\
\hline 8 & $\begin{array}{c}\text { Die } \\
\text { temperature }\end{array}$ & $\begin{array}{l}180- \\
200\end{array}$ & 180 & 200 \\
\hline 11 & Compressor & 6-8 bar & 5 bar & 7 bar \\
\hline 10 & Air pressure & $5-6$ & 5 & 6 \\
\hline 11 & Cycle time & 23 & 24 detik & 23 \\
\hline
\end{tabular}

\begin{tabular}{|c|c|c|c|c|}
\hline 12 & Berat netto & $\begin{array}{c}\text { detik } \\
22-23 \\
\text { gram }\end{array}$ & 21.5 & 22,4 \\
\hline
\end{tabular}

Hasil pengamatan terhadap jumlah defect dan melakukan kontrol parameter selama beberapa hari ditunjukkan pada Tabel 2.

Tabel 2 Jumlah defect perhari

\begin{tabular}{|c|c|c|c|c|c|}
\hline Tanggal & $\begin{array}{c}\text { jumlah } \\
\text { produksi } \\
\text { perhari } \\
\text { (pcs) }\end{array}$ & Bintik & Ulir & $\begin{array}{c}\text { Body } \\
\text { tipis } \\
\text { sebelah }\end{array}$ & $\begin{array}{c}\text { Produk } \\
\text { cacat } \\
\text { (pcs) }\end{array}$ \\
\hline $\begin{array}{c}11 \\
\text { februari }\end{array}$ & $\begin{array}{c}78.864 \\
\text { (shift 1) }\end{array}$ & 45 & 54 & 45 & 144 \\
\hline $\begin{array}{c}12 \\
\text { februari }\end{array}$ & $\begin{array}{c}78.864 \\
\text { (shift 1) }\end{array}$ & 36 & 52 & 46 & 136 \\
\hline $\begin{array}{c}18 \\
\text { februari }\end{array}$ & $\begin{array}{c}78.864 \\
\text { (shift 1) }\end{array}$ & 52 & 45 & 47 & 133 \\
\hline $\begin{array}{c}19 \\
\text { februari }\end{array}$ & $\begin{array}{c}78.864 \\
\text { (shift 1) }\end{array}$ & 45 & 36 & 48 & 129 \\
\hline
\end{tabular}

Dari hasil diatas menunjukkan bahwa setelah dilakukan kontrol parameter selama beberapa hari, jumlah produk yang mengalami cacat mengalami penurunan.

\section{KESIMPULAN}

Berdasarkan kajian yang dilakukan mengenai defect botol HDPE $180 \mathrm{ml}$ yang menggunakan mesin extrusion blow SMC B.11 di PT X, maka dapat diambil kesimpulan bahwa beberapa masalah yang sering terjadi pada saat proses extrusion blow terjadi yaitu, bitnik, ulir, dan body tipis sebelah. Solusi 
untuk penanganan bitnik pada botol mengurangi penggilingan aval atau flash yang di campur lagi dengan bahan yang baru, serta ulir dengan tiupan harus konsisten dengan tiupan angin 6 sampai 8 bar dan body tipis sebelah dengan menyetel di bagian head atau die pin dengan melakukan menaikan atau menurunkan ketebalan parison yang bengkok.

\section{REFERENSI}

Julianti, Sri. 2014. The Art of Packaging. Jakarta: PT Gramedia Pustaka Utama Maflahah, Iffan. 2016. Teknologi Pengemasan

M.S, Didik HM. 2017. Diktat Perkuliahan Program Studi Teknik Kemasan, Jurusan Teknik Grafika, Mata Kuliah Ilmu
Pengetahuan Plastik

M.S, Didik HM. 2017. Diktat Perkuliahan Program Studi Teknik Kemasan,

Jurusan Teknik Grafika, Mata Kuliah Pengantar Ilmu Kemasan

Soroka, Walter. Fundamental of Packaging Technology. United Kingdom (UK). The Institute of Packaging

Zulianto, Dwi. 2015. Analisa Pengaruh Variasi Suhu Plastik Terhadap Cacat Warpage pada Produk Injection Moulding

Sucipta, Nyoman. 2017. Pengemasan Pangan, Kajian Pengemasan yang Aman, Nyaman, dan Efisien

Ginting, Meriastuti. 2018. Minimalisasi Produk Cacat Proses Injection Mouldin 